\title{
Mixture of polysaccharide and nucleic acid extracted from Bacillus Calmette-Guerin (BCG) enhances immune response of infectious bursal disease virus vaccine in chickens
}

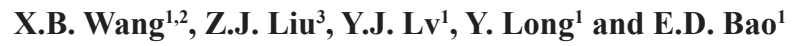 \\ ${ }^{1}$ College of Veterinary Medicine, Nanjing Agricultural University, Nanjing, \\ China \\ ${ }^{2}$ Laboratery Animal Centre, Southeast University, Nanjing, China \\ ${ }^{3}$ College of Animal Science and Technology, \\ Henan University of Science and Technology, Luoyang, China \\ Corresponding author: E.D. Bao \\ E-mail: b_endong@njau.edu.cn
}

Genet. Mol. Res. 15 (2): gmr.15025523

Received October 1, 2014

Accepted November 19, 2015

Published May 13, 2016

DOI http://dx.doi.org/10.4238/gmr.15025523

\begin{abstract}
In this study, the immune response induced by a mixture of polysaccharide and nucleic acid extracted from Bacillus CalmetteGuerin (BCG) was evaluated in chickens inoculated with infectious bursal disease virus (IBDV) vaccine. After the mixture was injected intramuscularly at a dose of $0.075,0.15$ or $0.3 \mathrm{mg} \cdot \mathrm{kg}^{-1} \cdot \mathrm{day}^{-1}$ for 3 days, the 14-day-old chickens were inoculated with the attenuated IBDV vaccine via intranasal and ocular routes. The relative weight of bursa of Fabricius (BF) and thymus, the serum IBD antibody titer, the CD4+/CD8+ ratio, and the concentrations of IFN- $\gamma$, IL-2 and IL-6 in peripheral blood were investigated on days 5, 15 and 25. The IBD antibody titer in BCG-treated groups was higher than in the negative control and only IBD-vaccinated chickens, indicating that the mixture of BCG can significantly enhance chicken humoral response. CD4+/
\end{abstract}


CD8+ and the secretions of IFN- $\gamma$, IL-2 and IL-6 were also clearly increased compared with that in the negative control and IBD-vaccinated chickens, indicating that the mixture can also enhance the cell-mediated immune response. The results also showed that the relative weights of $\mathrm{BF}$ and thymus increased after chickens were inoculated with BCG, indicating that the BCG mixture can clearly enhance the immunity of IBD-vaccine and can be expected to be viewed as a candidate for a new type of immune adjuvant.

Key words: Polysaccharide and nucleic acid; BCG; Chicken; Infectious bursal disease virus; Immune response

\section{INTRODUCTION}

Prevention and control of animal infectious diseases, especially viral diseases, mainly depend on vaccination of livestock. However, sometimes vaccine immune response has several disadvantages such as shorter duration of protection, lower cellular immune response and genotoxic potential, especially inactivated vaccine. Therefore, it is necessary to find an effective adjuvant to overcome these problems. At present, most research focuses on an immunopotentiator such as polyinosinic:polycytidylic acid (poly I:C) and Chinese herbal medicine (Hill, 1984; Fan et al., 2012). It can enhance immunity activities of animals themselves or synergistically enhance the immune effect of vaccine or act as an adjuvant to enhance the immune effect of the vaccine.

Bacillus Calmette-Guerin (BCG) is an attenuated form of Mycobacterium bovis, which is used in the prevention of Mycobacterium tuberculosis (Siddiqui et al., 2012). It can trigger the activation of innate immunity and the subsequent development of antigenspecific adaptive immunity by toll-like receptors (TLRs), such as TLR2 and TLR4 (Tsuji et al., 2000; Gilleron et al., 2006; Bastos et al., 2007; Méndez-Samperio et al., 2008). Because of immunity enhancement, dead cells of $M$. bovis BCG are found in complete Freund's adjuvant, which can enhance host immune responses, and living cells of M. bovis BCG have been extensively applied in immunotherapy of human cancers and experimental studies (Mathé et al., 1973; Kato et al., 2010; Vita et al., 2011). However, without completely extinguishing BCG, mycobacterial infection could occur, or osteoarticular infections and bilateral symmetric polyarthritis in the wrists and fingers may develop (Clavel et al., 2006). Therefore, many constituents are separated from BCG and reported as effective immune adjuvants, such as the cell wall skeleton of BCG (Ishii et al., 2005; Kato et al., 2010), muramyl dipeptide from the cell wall of BCG (Ellouz et al., 1974; Kleinerman et al., 1991) and methanol extraction residue of BCG (Hill, 1984). In addition, infectious bursa disease (IBD) is a immunosuppressive viral disease of chickens, attacking mainly an important lymphoid organ in birds, and immunosuppression can lead to increased susceptibility to diseases, such as Newcastle disease (Mahgoub et al., 2012; Rautenschlein et al., 2002b). Thus, IBD always causes great damage to livestock. In this study, a mixture of polysaccharide and nucleic acid was extracted from BCG by a hot phenol method and was used to elevate the immune activity of the mixture combined with IBD vaccine. 


\section{MATERIAL AND METHODS}

\section{Materials and reagents}

M. bovis BCG was purchased from the National Vaccine \& Serum Institute (Beijing, China). Attenuated IBD vaccine was donated by the Institute of Veterinary Medicine, Jiangsu Academy of Agricultural Science. The antibodies used in flow cytometry included mouse anti-chicken CD3-FITC, mouse anti-chicken CD8-R-PE and mouse anti-chicken CD4-R-PE (Southern Biotech, Birmingham, AL, USA).

\section{Preparation of polysaccharide nucleic acid fraction of BCG (BCG-PSN)}

M. bovis BCG cells $(2.0 \mathrm{~g})$ were suspended in $40 \mathrm{~mL} 0.9 \% \mathrm{NaCl}$ solution, and then disrupted by the ultrasonic method at $0^{\circ} \mathrm{C}$ for $10 \mathrm{~min}$. The disrupted cell suspension was mixed with an equal volume of hot $95 \%$ phenol solution, and the mixture was then kept at $4{ }^{\circ} \mathrm{C}$ overnight. The upper suspension was obtained after the mixture was centrifuged at $7000 \mathrm{rpm}$ for $20 \mathrm{~min}$ at $4^{\circ} \mathrm{C}$, and the suspension was then placed in a bag filter to remove the phenol. Ethanol was added to the supernatant to yield a $75 \%$ ethanolic solution, and the suspension was kept at $4{ }^{\circ} \mathrm{C}$ overnight. The precipitate was collected and lyophilized to yield a mixture of polysaccharide and nucleic acid (BCG-PSN). The polysaccharide portion was determined by the phenol-sulfuric acid method, using glucose as the standard. The nucleic acid portion was determined by a spectrophotometric method. The content $(\mathrm{w} / \mathrm{w})$ of polysaccharide and nucleic acid in the mixture was 72.6 and $23.5 \%$, respectively.

\section{Experimental design}

One hundred and fifty one-day-old White Roman chickens (male) obtained from Qinglongshan Poultry Farm were housed in wire cages $(60 \times 100 \mathrm{~cm})$ in air-conditioned rooms at $37^{\circ} \mathrm{C}$ and lighted for $24 \mathrm{~h}$ at the beginning of the pretrial period. The room temperature was gradually lowered to $25^{\circ} \mathrm{C}$ and the light period to $12 \mathrm{~h}$ per day. Chickens were fed with the commercial starter diet provided by the feed factory of Jiangsu Academy of Agricultural Science. The chickens were then randomly divided into five groups: negative control group, vaccine group, $0.3 \mathrm{mg} \cdot \mathrm{kg}^{-1} \cdot \mathrm{day}^{-1}$ BCG-PSN group, $0.15 \mathrm{mg} \cdot \mathrm{kg}^{-1} \cdot$ day $^{-1}$ BCG-PSN group and $0.075 \mathrm{mg} \cdot \mathrm{kg}^{-1} \cdot$ day $^{-1}$ BCG-PSN group (thirty chickens in each group). Except for the negative control group, all experimental chickens were inoculated with IBD vaccine at 14 days old by intranasal and instillation method (the negative control chickens inoculated with physiological saline). Before vaccine, all BCG-PSN-treated chickens were intramuscularly injected with different concentrations of BCG-PSN once a day for three successive days. After inoculation, the bursa and thymus from each experimental group (five chickens per group) were collected and weighted at 5, 15, and 25 days. The relative weight of the bursa and thymus was calculated as a proportion of each animal's body weight. Peripheral blood was collected from each group, and the serum was obtained to determine the anti-IBDV antibody titer and the concentrations of IFN- $\gamma$, IL-2 and IL-6. Heparinized blood was collected from each group for flow cytometry analysis.

\section{Determination of anti-IBDV antibody titer}

The antibody titer of IBDV was determined according to the instructions given in the 
commercial antibody-capture ELISA kit (Biochek, the Netherlands). The relative antibody titer in the unknown wells was determined by calculating the sample to positive $(\mathrm{S} / \mathrm{P})$ ratio. Endpoint titers were calculated by the equation: $\log 10$ titer $=1.1(\log 10 \mathrm{~S} / \mathrm{P})+3.361$.

\section{Flow cytometry analysis of peripheral blood lymphocyte subpopulation}

Lymphocytes were isolated from heparinized blood using Lymphocyte Separation Medium (Sigma, USA). The separated cells were treated with anti-chicken CD3+-FITC, anti-chicken CD8+-R-PE and anti-chicken CD4+-R-PE monoclonal antibody, followed by washing with phosphate-buffered saline to remove unbound antibody. The percentage of $\mathrm{CD} 4+\mathrm{T}$ or $\mathrm{CD} 8+\mathrm{T}$ cells was measured by the flow cytometric method using a FACSCalibur ${ }^{\mathrm{TM}}$ flow cytometer (BD Biosciences Co. Ltd. Shanghai, China).

\section{Determination of serum IFN- $\gamma$, IL-2 and IL-6}

Serum levels of IFN- $\gamma$, IL-2 and IL-6 were measured according to the instructions given in the commercial ELISA kits (SUNBIO Biological Co. Ltd., Beijing, China).

\section{Statistical analysis}

All data are reported as means \pm standard deviation. Assays were performed in triplicate. Statistical analysis of the differences between each group was carried out using a oneway analysis of variance (ANOVA) using the Statistical Package for Social Sciences (SPASS 11.5). Comparison of the mean value of the control group with that of each experimental group was performed using the Duncan test for multiple comparisons. Differences were regarded as significant at $\mathrm{P}<0.05$.

\section{RESULTS}

\section{Changes in relative weight of the bursa and thymus}

The relative weight of the bursa is presented in the Figure 1. After injection, there was no significant difference with respect to the relative weight of the bursa among five groups on day $5(\mathrm{P}>0.05)$. However, on days 15 and 25 , the relative weight of the bursa increased with dose of BCG-PSN, and the relative weight of the bursa in the middle- and high-dose groups were significantly higher than that in the negative control group, vaccine group and low-dose group $(\mathrm{P}<0.05)$. The relative weight of the thymus is shown in Figure 2. After injection, the relative weights of the thymus in the low-, middle- and high-dose groups were significantly higher than that in the negative control and vaccine group on day $5(\mathrm{P}<0.05)$. On days 15 and 25 , the relative weights of the thymus in the middle- and high-dose groups were significantly higher than that in the negative control and vaccine group $(\mathrm{P}<0.05)$.

\section{Changes in IBDV antibody titer}

The IBDV antibody titers in each group are shown in Figure 3. After injection, the antibody titers in the vaccine group and low-, middle- and high-dose groups were significantly 
higher than that in the control group on day $5(\mathrm{P}<0.05)$. However, there were no statistical differences between the vaccine group and low-, middle- and high-dose groups $(\mathrm{P}>0.05)$. On day 15 , the antibody titers in the three BCG-PSN dose groups (low, middle and high dose) were significantly higher than those in the negative control group and vaccine group $(\mathrm{P}<$ $0.05)$, and the antibody titers in the middle- and high-dose groups were significantly higher than those in the low-dose group $(\mathrm{P}>0.05)$. On day 25 , the antibody titers in the low-, middleand high-dose BCG-PSN groups were significantly higher than that in the negative control and vaccine groups $(\mathrm{P}<0.05)$, and the antibody titers in middle- and high-dose groups were significantly higher than those in the low-dose group $(\mathrm{P}<0.05)$.

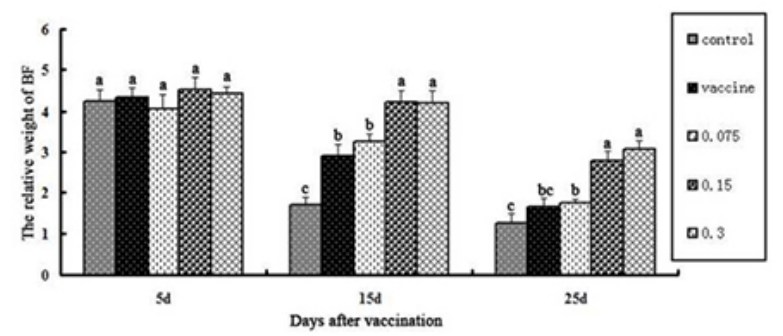

Figure 1. Changes of relative weight of $\mathrm{BF}$ in different groups on days 5, 15 and 25 after vaccination. Bars with different letters differ significantly $(\mathrm{P}<0.05)$. Data are reported as means $\pm \mathrm{SD}, \mathrm{N}=5$.

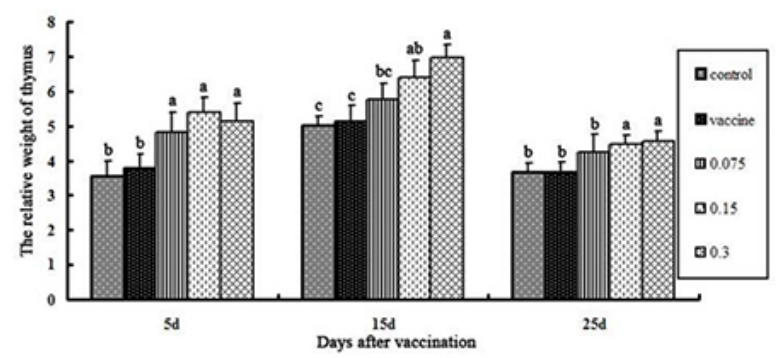

Figure 2. Changes of relative weight of thymus in different groups on days 5,15 and 25 after vaccination. Bars with different letters differ significantly $(\mathrm{P}<0.05)$. Data are reported as means $\pm \mathrm{SD}, \mathrm{N}=5$.

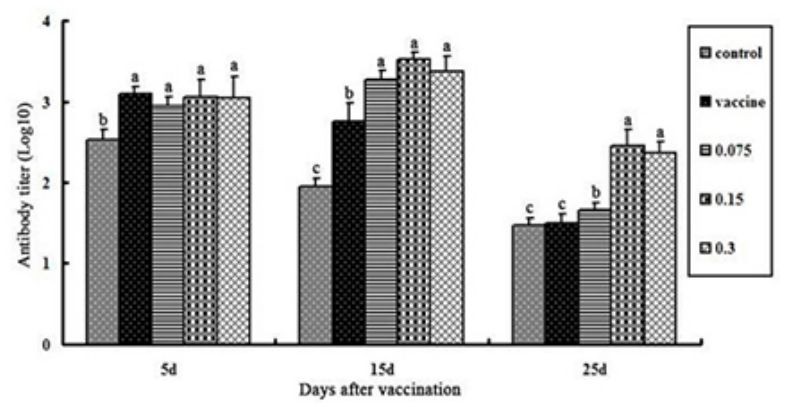

Figure 3. Changes of antibody titers in different groups on days 5, 15 and 25 after vaccination. Bars with different letters differ significantly $(\mathrm{P}<0.05)$. Data are reported as means $\pm \mathrm{SD}, \mathrm{N}=5$. 


\section{Changes in CD4+ to CD8+ ratio}

The ratios of $\mathrm{CD} 4+$ to $\mathrm{CD} 8+(\mathrm{CD} 4+/ \mathrm{CD} 8+)$ are presented in Figure 4. On day 5 after injection, there were no significant differences between the five groups $(\mathrm{P}>0.05)$. CD4+/ CD8+ in all BCG-PSN dose groups and in the vaccine group were significantly higher than those in the negative control group on day $15(\mathrm{P}<0.05)$, and $\mathrm{CD} 4+/ \mathrm{CD} 8+$ in the high-dose group was significantly higher than that in the vaccine group $(\mathrm{P}<0.05)$. On day 25 after injection, $\mathrm{CD} 4+/ \mathrm{CD} 8+$ in the middle- and high-dose groups were significantly higher than those in the negative control, vaccine and low-dose groups $(\mathrm{P}<0.05)$.

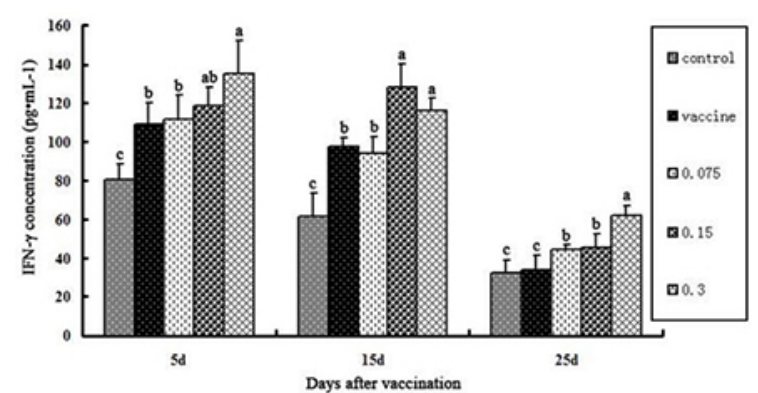

Figure 4. Changes of the ratios of CD8+ and CD4+ in different groups on days 5, 15 and 25 after vaccination. Bars with different letters differ significantly $(\mathrm{P}<0.05)$. Data are reported as means $\pm \mathrm{SD}, \mathrm{N}=5$.

\section{Changes in IFN- $\gamma$ concentration}

The changes in serum IFN- $\gamma$ concentration are presented in Figure 5. On day 5 after vaccination, the concentration of IFN- $\gamma$ in the high-dose group was significantly higher than that in the negative control, vaccine and low- and middle-dose groups $(\mathrm{P}<0.05)$. On day 15 after vaccination, the concentrations of IFN- $\gamma$ in the middle- and high-dose groups were significantly higher than those in the negative control, vaccine and low-dose groups $(\mathrm{P}<$ $0.05)$. However, there was no difference between the middle- and high-dose groups $(\mathrm{P}>0.05)$. On day 25 after vaccination, the concentrations of IFN- $\gamma$ in all BCG-PSN dose groups were significantly higher than those in the negative control and vaccine groups $(\mathrm{P}<0.05)$, and the concentration of serum IFN- $\gamma$ in the high-dose group was significantly higher than that in the low- and middle-dose groups $(\mathrm{P}<0.05)$.

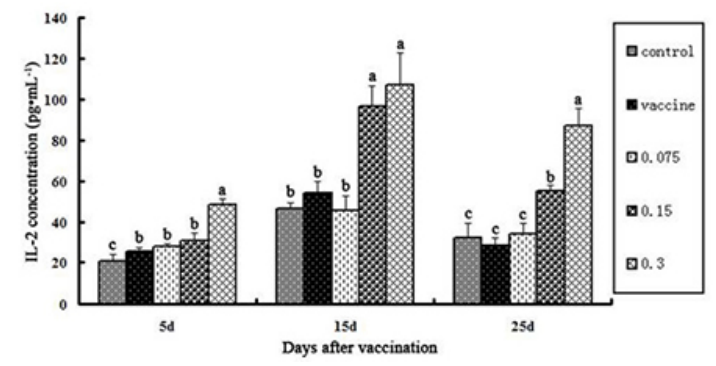

Figure 5. Changes of IFN- $\gamma$ concentrations in different groups on days 5, 15 and 25 after vaccination. Bars with different letters differ significantly $(\mathrm{P}<0.05)$. Data are reported as means $\pm \mathrm{SD}, \mathrm{N}=5$. 


\section{Changes in serum IL-2 concentration}

The changes of serum IL-2 concentration are presented in Figure 6. On day 5 after vaccination, the IL-2 concentration in the high-dose BCG-PSN group was significantly higher than that in the low- and middle-dose BCG-PSN, negative control and vaccine groups $(\mathrm{P}<$ $0.05)$. On day 15 after vaccination, the IL-2 concentrations in the middle- and high-dose BCGPSN groups were significantly higher than those in the negative control, vaccine and low-dose groups $(\mathrm{P}<0.05)$, and there was no difference between the middle- and high-dose groups $(\mathrm{P}>$ $0.05)$. On day 25 after vaccination, the IL-2 concentrations in the middle- and high-dose BCGPSN groups were significantly higher than that in the negative control, vaccine and low dose groups $(\mathrm{P}<0.05)$, and the IL-2 concentration in the high dose group was significantly higher than that in the middle dose group $(\mathrm{P}<0.05)$.

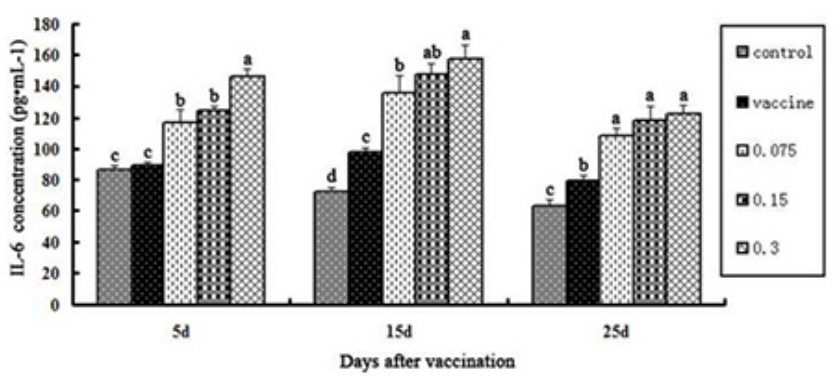

Figure 6. Changes of IL-2 concentrations in different groups on days 5, 15 and 25 after vaccination. Bars with different letters differ significantly $(\mathrm{P}<0.05)$. Data are reported as means $\pm \mathrm{SD}, \mathrm{N}=5$.

\section{Changes in serum IL-6 concentration}

The changes in serum IL-6 concentration are presented in Figure 7. From day 5 to day 25 after vaccination, the serum IL-6 concentrations in all BCG-PSN dose groups were significantly higher than those in the negative control and vaccine groups $(\mathrm{P}<0.05)$.

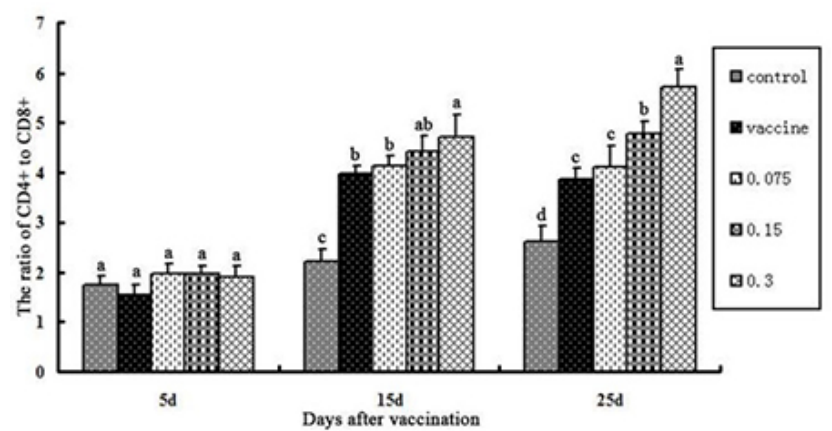

Figure 7. Changes of IL-6 concentrations in different groups on days 5, 15 and 25 after vaccination. Bars with different letters differ significantly $(\mathrm{P}<0.05)$. Data are expressed as means $\pm \mathrm{SD}, \mathrm{N}=5$. 


\section{DISCUSSION}

$\mathrm{BF}$, acknowledged as a humoral organ unique to chickens, is the main site of $\mathrm{B}$ cell development and maturation. Once infected with IBDV, BF of chickens is always damaged, resulting in lower immunity and susceptibility to infection by other pathogens (Rautenschlein et al., 2002a; Mahgoub et al., 2012). The thymus is the main site of T cell development and maturation and is related to cell-mediated immunity. The relative weights of the BF and thymus are usually regarded as indices to elevate the immunity activity. In present study, the relative weights of $\mathrm{BF}$ were significantly higher than that in the negative control and vaccine groups from day 15 to 25 after vaccination with 0.15 or $0.3 \mathrm{mg} \cdot \mathrm{kg}^{-1} \cdot \mathrm{day}^{-1} \mathrm{BCG}-\mathrm{PSN}$. The relative weights of thymus in all BCG-PSN dose groups on day 5 after vaccination, and in the 0.15 and $0.3 \mathrm{mg} \cdot \mathrm{kg}^{-1} \cdot \mathrm{day}^{-1} \mathrm{BCG}-\mathrm{PSN}$ groups from day 15 to 25 after vaccination were significantly higher than those in the negative control and vaccine groups. These results demonstrated that the BCG-PSN could promote the development of BF and thymus, and was helpful in enhancing the animal's immunity.

Both humoral immunity and cell-mediated immune response can be enhanced by BCG-PSN. Humoral immunity mediated by B lymphocytes is one of the main factors to combat infectious diseases as an important specific immune response. The antibody level is the marker reflecting humoral immune function in animals. In the present study, the antibody titers of IBDV in the 0.15 and $0.3 \mathrm{mg} \cdot \mathrm{kg}^{-1} \cdot \mathrm{day}^{-1}$ BCG-PSN groups were significantly higher than those in the negative control and vaccine groups from day 15 to 25 , indicating that BCG-PSN had the ability to enhance humoral immunity. Although antibodies are considered to be an important element in the protective immune response against IBDV, cell-mediated responses are also critical (Rautenschlein et al., 2002a). T cells mediate a variety of helpful and effective functions, in particular cytolytic activity, activation of macrophages, and immunological memory (Li et al., 2011). CD4+ T cells represent a major $\mathrm{T}$ cell population and are well known as Thelper cells mainly associated with the Th1 and Th2 immune responses via the production of Th1 cytokines and increased antibody section, respectively. CD8+ T cells, also known as cytotoxic T cells, play an important role in immune protection against intracellular pathogens. Thus, enhanced populations of these $\mathrm{T}$ cells in the immunized host are very important. Our preliminary results showed that $\mathrm{CD} 4+/ \mathrm{CD} 8+$ in the 0.15 and $0.3 \mathrm{mg} \cdot \mathrm{kg}^{-1} \cdot \mathrm{day}^{-1}$ BCG-PSN groups 15 days after vaccination was significantly higher than that in the negative control and vaccine groups, indicating that BCG-PSN could also enhance cell-mediated immune responses.

The cytokine proteins IFN- $\gamma$ and IL- 2 are secreted by Th1 cells and can promote the proliferation and differentiation of $\mathrm{T}$ cells, which are always regarded as an important indicator of cellular immunity function (Farrar and Schreiber, 1993; Li et al., 2004; Fan et al., 2012). Moreover, it has been reported that IFN- $\gamma$ and IL-2 can be used as adjuvants to enhance antigen presentation, $\mathrm{T}$ cell immune response and $\mathrm{B}$ cell humoral immune response (Lowenthal et al., 1998; Li et al., 2004; Kumar et al., 2009). In this study, the concentrations of serum IFN- $\gamma$ in the $0.3 \mathrm{mg} \cdot \mathrm{kg}^{-1}$. day $^{-1}$ BCG-PSN group on days 5 and 25 , and in the 0.15 and 0.3 $\mathrm{mg} \cdot \mathrm{kg}^{-1} \cdot$ day $^{-1} \mathrm{BCG}$-PSN groups on day 15 after vaccination were significantly higher than that in the negative control and vaccine group. The concentrations of serum IL-2 in the $0.3 \mathrm{mg} \cdot \mathrm{kg}$ 1. day $^{-1}$ BCG-PSN group on day 5 , and in the 0.15 and $0.3 \mathrm{mg} \cdot \mathrm{kg}^{-1}$. day $^{-1}$ BCG-PSN groups on days 15 and 25 after vaccination were significantly higher than those in the negative control and vaccine group. This indicated that BCG-PSN could enhance cell-mediated immunity. This

result correlated with the increase in $\mathrm{CD} 4+/ \mathrm{CD} 8+\mathrm{T}$ ratio. The cytokine protein IL-6 is secreted 
by Th2 cells and can promote the proliferation of B cells and the production of antibody, which plays an important role in humoral immunity (Belardelli, 1995; Fan et al., 2012). In the present study, the concentrations of serum IL- 6 in the $0.3 \mathrm{mg} \cdot \mathrm{kg}^{-1} \cdot$ day $^{-1}$ BCG-PSN group on day 5 , and in the $0.075,0.15$ and $0.3 \mathrm{mg} \cdot \mathrm{kg}^{-1} \cdot$ day $^{-1}$ BCG-PSN groups on days 15 and 25 after vaccination were significantly higher than those in the negative control and vaccine groups, indicating that BCG-PSN could enhance huromal immunity. This result correlated with the increase in antibody titers. Although humoral and cell-mediated immunity could be enhanced by BCG-PSN, the immunity effect of polysaccharide or nucleic acid alone was not studied. This potential limitation should be considered in future studies.

In conclusion, the BCG-PSN mixture extracted from BCG has the ability to synergistically enhance the humoral immunity and cell-mediated immune effect of IBDV vaccine in chickens, and it would be expected to be a candidate for a new type of immunologic adjuvant.

\section{Conflicts of interests}

The authors declare that no conflict of interests exists.

\section{ACKNOWLEDGMENTS}

Research supported by a Project Fund, Priority Academic Program Development of Jiangsu Higher Education Institutions (PAPD) and Youth Science and Technology Innovation Fund of Nanjing Agricultural University (Grant \#KJ2010015).

\section{REFERENCES}

Bastos RG, Johnson WC, Brown WC and Goff WL (2007). Differential response of splenic monocytes and DC from cattle to microbial stimulation with Mycobacterium bovis BCG and Babesia bovis merozoites. Vet. Immunol. Immunopathol. 115: 334-345. http://dx.doi.org/10.1016/j.vetimm.2006.11.001

Belardelli F (1995). Role of interferons and other cytokines in the regulation of the immune response. APMIS 103: 161179. http://dx.doi.org/10.1111/j.1699-0463.1995.tb01092.x

Clavel G, Grados F, Lefauveau P and Fardellone P (2006). Osteoarticular side effects of BCG therapy. Joint Bone Spine 73: 24-28.http://dx.doi.org/10.1016/j.jbspin.2004.12.003

Ellouz F, Adam A, Ciorbaru R and Lederer E (1974). Minimal structural requirements for adjuvant activity of bacterial peptidoglycan derivatives. Biochem. Biophys. Res. Commun. 59: 1317-1325. http://dx.doi.org/10.1016/0006$\underline{291 X(74) 90458-6}$

Fan Y, Wang D, Hu Y, Liu J, et al. (2012). Liposome and epimedium polysaccharide-propolis flavone can synergistically enhance immune effect of vaccine. Int. J. Biol. Macromol. 50: 125-130. http://dx.doi.org/10.1016/j. ijbiomac.2011.10.008

Farrar MA and Schreiber RD (1993). The molecular cell biology of interferon-gamma and its receptor. Аnnu. Rev. Immunol. 11: 571-611. http://dx.doi.org/10.1146/annurev.iy.11.040193.003035

Gilleron M, Nigou J, Nicolle D, Quesniaux V, et al. (2006). The acylation state of mycobacterial lipomannans modulates innate immunity response through toll-like receptor 2. Chem. Biol. 13: 39-47. http://dx.doi.org/10.1016/j. chembiol.2005.10.013

Hill CA (1984). Thoracic tuberculosis, mycobacteriosis, MERosis, and BCGosis in a cancer treatment center. Radiology 153: 311-316. http://dx.doi.org/10.1148/radiology.153.2.6484160

Ishii K, Kurita-Taniguchi M, Aoki M, Kimura T, et al. (2005). Gene-inducing program of human dendritic cells in response to BCG cell-wall skeleton (CWS), which reflects adjuvancy required for tumor immunotherapy. Immunol. Lett. 98: 280-290. http://dx.doi.org/10.1016/j.imlet.2004.12.002

Kato T, Bilim V, Yuuki K, Naito S, et al. (2010). Bacillus Calmette-Guerin and BCG cell wall skeleton suppressed viability of bladder cancer cells in vitro. Anticancer Res. 30: 4089-4096. 
Kleinerman ES, Snyder JS and Jaffe N (1991). Influence of chemotherapy administration on monocyte activation by liposomal muramyl tripeptide phosphatidylethanolamine in children with osteosarcoma. J. Clin. Oncol. 9: 259-267.

Kumar S, Ahi YS, Salunkhe SS, Koul M, et al. (2009). Effective protection by high efficiency bicistronic DNA vaccine against infectious bursal disease virus expressing VP2 protein and chicken IL-2. Vaccine 27: 864-869. http://dx.doi. org/10.1016/j.vaccine.2008.11.085

Li J, Liang X, Huang Y, Meng S, et al. (2004). Enhancement of the immunogenicity of DNA vaccine against infectious bursal disease virus by co-delivery with plasmid encoding chicken interleukin 2. Virology 329: 89-100. http://dx.doi. org/10.1016/j.virol.2004.07.033

Li J, Zhong Y, Li H, Zhang N, et al. (2011). Enhancement of Astragalus polysaccharide on the immune responses in pigs inoculated with foot-and-mouth disease virus vaccine. Int. J. Biol. Macromol. 49: 362-368. http://dx.doi. org/10.1016/j.ijbiomac.2011.05.015

Lowenthal JW, O'Neil TE, Broadway M, Strom ADG, et al. (1998). Coadministration of IFN- $\gamma$ enhances antibody responses in chickens. J. Interferon Cytokine Res. 18: 617-622.http://dx.doi.org/10.1089/jir.1998.18.617

Méndez-Samperio P, Belmont L and Miranda E (2008). Mycobacterium bovis BCG Toll-like receptors 2 and 4 cooperation increases the innate epithelial immune response. Arch. Med. Res. 39: 33-39. http://dx.doi.org/10.1016/j. arcmed.2007.06.019

Mahgoub HA, Bailey M and Kaiser P (2012). An overview of infectious bursal disease. Arch. Virol. 157: 2047-2057. http://dx.doi.org/10.1007/s00705-012-1377-9

Mathé G, Kamel M, Dezfulian M, Halle-Pannenko O, et al. (1973). An experimental screening for "systemic adjuvants of immunity" applicable in cancer immunotherapy. Cancer Res. 33: 1987-1997.

Rautenschlein S, Yeh H-Y, Njenga MK and Sharma JM (2002a). Role of intrabursal T cells in infectious bursal disease virus (IBDV) infection: T cells promote viral clearance but delay follicular recovery. Arch. Virol. 147: 285-304. http://dx.doi.org/10.1007/s705-002-8320-2

Rautenschlein S, Yeh H-Y and Sharma JM (2002b). The role of T cells in protection by an inactivated infectious bursal disease virus vaccine. Vet. Immunol. Immunopathol. 89: 159-167.http://dx.doi.org/10.1016/S0165-2427(02)00202-7

Siddiqui N, Price S and Hope J (2012). BCG vaccination of neonatal calves: potential roles for innate immune cells in the induction of protective immunity. Comp. Immunol. Microbiol. Infect. Dis. 35: 219-226. http://dx.doi.org/10.1016/j. $\underline{\text { cimid.2011.11.003 }}$

Tsuji S, Matsumoto M, Takeuchi O, Akira S, et al. (2000). Maturation of human dendritic cells by cell wall skeleton of Mycobacterium bovis bacillus Calmette-Guérin: involvement of toll-like receptors. Infect. Immun. 68: 6883-6890. http://dx.doi.org/10.1128/IAI.68.12.6883-6890.2000

Vita F, Siracusano S, Abbate R, Ciciliato S, et al. (2011). BCG prophylaxis in bladder cancer produces activation of recruited neutrophils. Can. J. Urol. 18: 5517-5523. 